\title{
UJI AKTIVITAS LARVASIDA EKSTRAK DAUN JARAK KEPYAR (Ricinus communis L.) TERHADAP LARVA NYAMUK Aedes aegypti
}

\author{
Wahyu Wira Utami ${ }^{1}$, Aktsar Roskiana Ahmad, Abd.Malik \\ Fakultas Farmasi, Universitas Muslim Indonesia \\ 1 mhytautami@gmail.com
}

\begin{abstract}
Castor Plant (Ricinus communis L.) belongs to Euphorbiaceae family. In medicine has been used as antioxidant, antihistaminic, antifertility, antimicrobial, antidiabetic, antiinflammatory, antipyretic, and it has activities to larvacidal, molluscicidal and insecticidal. The aim of this study was to determine the level of mosquito larva (Aedes aegypti) mortality after giving of ethanolic extract showed with LC50. Extract obtained by maceration method, rendamen ethanolic extract obtained as much as 6.073\%. This research uses 110 instar, III larvae of mosquito (Aedes aegypti), divided into test solution are made with 3 concentrations $(10 \mu \mathrm{g} / \mathrm{mL}, 100$ $\mu \mathrm{g} / \mathrm{mL}, 1000 \mu \mathrm{g} / \mathrm{mL})$, positive control using Abate and negative control using water. Observations were made after 24 hours of treatment. Toxicity test results shows ethanolic extract is an extract that is active as Larvacidal showed LC50 as much as 138,995 $\pm 1,5 \mu \mathrm{g} / \mathrm{mL}<1000 \mu \mathrm{g} / \mathrm{mL}$. Based on qualitative testing of the chemical component using TLC method known ethanolic extract of Castor Plant (Ricinus communis L.) leaves contain alcaloids, saponins and flavonoids.
\end{abstract}

Keywords : Aedes aegypti, Castor Plant leaves, Larvacidal, LC50, Ricinus communis L

\section{PENDAhuluan}

\section{A. Latar Belakang}

Jarak kepyar merupakan salah satu tanaman yang digunakan sebagai obat. Bagian yang digunakan adalah bagian daun dalam bentuk segar kemudian dikeringkan. Tanaman ini mengandung kaemferol-3rutinoside, nikotiflorin, Isoqiersitrin, kaemferol, kuersetin, astragalin yang memiliki kemampuan untuk melawan beberapa penyakit, seperti koreng, gatal, batuk sesak dan hernia (Widodo dan Sumarsih, 2007).

Daun jarak kepyar (Ricinus communis L.) mengandung saponin (Sinaga, 2013) diduga dapat berpengaruh terhadap pertumbuhan larva nyamuk. Hal ini dikemukakan pula oleh Aminah (2001) bahwa saponin dapat menurunkan tegangan permukaan selaput mukosa traktus digestivus larva sehingga dinding traktus digestivus menjadi korosif.

Nyamuk pada umumnya dan Aedes aegypti pada khususnya merupakan masalah cukup besar yang menyangkut kesehatan masyarakat di negara-negara dengan iklim tropis termasuk Indonesia. Aedes aegypti merupakan faktor dari beberapa penyakit serius yang menyerang manusia seperti malaria, encephalitis, "yelow fever", demam dengue, demam berdarah dengue, filariasis, dan arbovirus. Salah satu masalah besar yang ditimbulkan oleh nyamuk Aedes aegypti di Indonesia adalah demam dengue dan demam berdarah dengue. Dimana salah satu upaya untuk pencegahan penyakit tersebut adalah dengan menggunakan tanaman obat-obat herbal (Ndione, 2007).

Hingga saat ini cara pencegahan atau pemberantasan Demam Berdarah Dengue (DBD) yang dapat dilaksanakan dengan memberantas vektor untuk memutuskan rantai penularan. Salah satu pemberantasan ditujukan pada larva Aedes aegypti. Cara yang biasa digunakan untuk membunuh larva adalah dengan menggunakan larvasida (Ndione, 2007).

Berdasarkan beberapa literatur yang ada bahwa saponin diduga dapat berpengaruh terhadap pertumbuhan larva nyamuk (Cania dan Setyaningrum, 2012). Maka penelitian yang akan dilakukan meliputi uji aktivitas larvasida ekstrak daun jarak kepyar (Ricinus communis L.) yang akan dilakukan pada hewan coba larva nyamuk Aedes aegypti.

\section{METODE PENELITIAN}

\section{A. Pengambilan dan Pengolahan Sampel}

Sampel Daun jarak kepyar (Ricinus communis L.) diambil di Kota Jeneponto, Sulawesi Selatan. Sampel kemudian dibersihkan dari kotoran yang melekat lalu dikeringkan dengan cara dianginanginkan dan disimpan di lemari pengering. Setelah kering, daun Jarak kepyar (Ricinus communis L.) diblender sampai menjadi serbuk, disimpan ke dalam wadah dan siap untuk diekstraksi. 


\section{B. Ekstraksi Sampel}

Sampel daun jarak kepyar (Ricinus communis L.) dimasukkan ke dalam wadah maserasi, lalu ditambahkan pelarut etanol hingga simplisia tersebut terendam, dibiarkan selama 3 hari dalam bejana tertutup dan terlindungi dari cahaya matahari langsung sambil diaduk secara periodik, setelah $3 \mathrm{x}$ 24 jam dilakukan penyaringan untuk diperoleh ekstrak etanol cair. Setelah itu, ampasnya dimaserasi kembali dengan cairan penyari yang baru. Hasil penyarian yang diperoleh kemudian diuapkan dengan menggunakan rotavapor dan kemudian dihasilkan ekstrak etanol kental (Andriani, 2008).

\section{Uji Larvasida}

Pengujian larvasida meliputi (Aradilla, 2009):

\section{Penyiapan Larva Nyamuk \\ a. Kriteria Inklusi}

1. Larva Aedes aegypti sehat yang telah mencapai instar III / IV.

2. Larva bergerak aktif.

\section{b. Kriteria Eksklusi}

1. Larva Aedes aegypti yang belum mencapai instar III / IV.

2. Larva yang telah berubah menjadi pupa ataupun nyamuk dewasa.

3. Larva yang mati sebelum perlakuan.

Larva nyamuk Aedes aegypti, diperoleh dari Laboratorium Entomologi Universitas Hasanuddin yang sebelumnya telah diidentifikasi oleh ahli serangga. Telur nyamuk Aedes aegypti juga dapat diperoleh dengan membuat wadah penampungan air yang telah dipasangi kertas saring untuk menjaring telur nyamuk yang mengapung. Telur Aedes aegypti berwarna putih saat pertama kali dikeluarkan, lalu menjadi coklat kehitaman juga tidak berkelompok. Telur berbenuk oval dan panjang kurang lebih $0,5 \mathrm{~mm}$. Telur nyamuk ditetaskan dalam nampan plastik berisi air bersih \pm 1000 cc. Larva yang telah menetas diberi makan fish food setiap hari. Larva-larva tersebut dipelihara sampai stadium IV, kurang lebih selama 6 hari, kemudian digunakan untuk penelitian (Aradilla, 2009).

\section{Pembagian Kelompok}

Larutan yang telah dipersiapkan yang berisi ekstrak etanol daun jarak kepyar, dipindahkan ke dalam kontainer yang telah dipersiapkan dan dibagi menjadi 5 kelompok perlakuan dengan 2 kontrol. Dengan pembagian sebagai berikut :

a. Kelompok A: ekstrak etanol daun jarak kepyar konsentrasi $10 \mu \mathrm{g} / \mathrm{mL}$.

b. Kelompok B: ekstrak etanol daun jarak kepyar konsentrasi $100 \mu \mathrm{g} / \mathrm{mL}$. c. Kelompok C: ekstrak etanol daun jarak kepyar konsentrasi $1000 \mu \mathrm{g} / \mathrm{mL}$

d. Kelompok D: abate sebagai kontrol positif

e. Kelompok E: air sebagai kontrol negative

Dalam penelitian ini larutan ekstrak etanol daun jarak dalam setiap kontainer tidak diganti selama percobaan, dan setiap konsentrasi dari kelompok percobaan direplikasi sebanyak tiga kali (Aradilla, 2009).

\section{Pemindahan Larva pada Kontainer}

a. Larva pada nampan plastik dipindahkan ke beker glass.

b. Dengan menggunakan pipet, ambil 10 ekor larva dan dimasukkan ke dalam vial yang berisi ekstrak etanol yang telah dibagi menjadi 3 kelompok dengan variasi konsentrasi yaitu $10 \mu \mathrm{g} / \mathrm{mL}, 100 \mu \mathrm{g} / \mathrm{mL}$ dan $1000 \mu \mathrm{g} / \mathrm{mL}$ dan juga 2 kontrol yaitu kontrol positif (abate) dan kontrol negatif (air).

c. Setelah semua larva dipindahkan ke dalam kontainer, setiap Kelompok kontainer ditutup dengan kain.

d. Larva diberi makan fosh food selama penelitian

\section{Pengujian Larvasida}

Metode larvasida digunakan sebagai pengujian aktivitas larvasida terhadap larva nyamuk Aedes aegypti. Sebanyak 10 ekor larva nyamuk Aedes aegypti instar III dipindahkan dari wadah penampung ke dalam gelas piala yang berisi ekstrak (sesuai konsentrasi). Aktivitas larvasida yang diamati yaitu selama 24 jam. Perhitungan waktu di-mulai setelah pemasukkan larva ke dalam gelas piala. Pengamatan alur hidup yaitu larva uji diberikan ekstrak mampu bertahan hidup pada jangka waktu tertentu namun tidak dapat mencapai tahap selanjutnya. Efek kematian dimaksud yaitu larva uji mengalami mortalitas akibat adanya aktivitas ekstrak larvasida yang diberikan (Rahman et al., 2005).

\section{Skrining Fitokimia}

Pada penentuan komponen kimia yang dilakukan menggunakan lempeng KLT. Kromatogram disemprotkan dengan menggunakan beberapa perekasi golongan komponen kimia yaitu (Depkes RI, 1987):

\section{a. Alkaloid}

Ekstrak ditotolkan pada plat KLT, dielusi dengan eluen yang sesuai. Diamati bercak dan disemprot dengan pereaksi spesifik yaitu Dragendroff- $\mathrm{HCl}$ (warna noda jingga), Bauchardat (bercak berwarna coklat). 


\section{b. Flavonoid}

Ekstrak daun jarak kepyar ditotolkan pada plat KLT, dielusi dengan eluen yang sesuai. Diamati bercak dan disemprot dengan pereaksi spesifik yaitu sitroborat (pendaran dalam sinar UV $366 \quad \mathrm{~nm}$ ). $\mathrm{AlCl}_{3}$ (bercak berpendar pada sinar UV $366 \mathrm{~nm}$ ).

\section{c. Saponin}

Ekstrak daun jarak kepyar ditotolkan pada plat KLT, dielusi dengan eluen yang sesuai. Diamati bercak dan disemprot dengan pereaksi spesifik yaitu Vanilin-Asam sulfat $P$ yang menghasilkan bercak warna biru.

\section{E. Analisis Data}

Data dikumpulkan dari hasil jumlah larva yang mati dari tiap konsentrasi sampel dan control setelah 24 jam. Data tersebut selanjutnya dianalisis secara probit untuk memperoleh $\mathrm{LC}_{50}$.

\section{HASIL DAN PEMBAHASAN}

Daun jarak kepyar merupakan tumbuhan perdu atau pohon kecil, batang berongga, berlilin kebiruan. Daun kelilingnya bulat lingkaran, bercangap menjari, bergerigi, pada ujungnya dengan 2 kelenjar; daun penumpu bersatu (Steenis, 1975).

Pada penelitian ini digunakan daun jarak kepyar sebanyak 450 gram dan kemudian diekstraksi dengan menggunakan metode maserasi yang merupakan salah satu metode ekstraksi dingin. Metode ini tidak merusak komponen kimia dari sampel daun jarak kepyar (Ricinus communis L.) karena tidak adanya pemanasan dalam proses ekstraksi (Dirjen POM, 1986).

Ekstrak etanol daun jarak kepyar yang diperoleh sebanyak 27,168 gram sehingga total rendamen yang diperoleh sebesar $6,037 \%(\mathrm{~b} / \mathrm{b})$ dari berat sampel awal. Setelah proses maserasi, penelitian dilanjutkan dengan melakukan pengujian hayati.

Tabel 1. Hasil rendamen ekstrak daun jarak kepyar (Ricinus communis L.)

\begin{tabular}{cccccc}
\hline No. & Jenis Pelarut & Bobot Simplisia $(\mathbf{g})$ & $\begin{array}{c}\text { Jumlah plearut } \\
(\mathbf{m L})\end{array}$ & $\begin{array}{c}\text { Hasil Ekstrak } \\
(\mathbf{g})\end{array}$ & $\begin{array}{c}\text { Rendamen } \\
\text { Ekstrak (\%) }\end{array}$ \\
\hline $\mathbf{1}$ & Etanol & 450 & 2000 & 27,1681 & 6,037 \\
\hline
\end{tabular}

Pada pengujian larvasida (Aedes aegypti) nilai $\mathrm{LC}_{50}$ dapat dihitung dengan menggunakan program komputer Finney seperti yang disebutkan dalam kasus uji Brine Shrimp Lehality Test (BSLT) (Rahman, 2005), dimana pengujian ini dimaksudkan sebagai pengujian dasar/praskrining untuk senyawasenyawa yang diduga memiliki sifat sitotoksik. Pengujian ini dipilih karena waktu yang diperlukan relatif lebih cepat, murah, sederhana (tidak memerlukan keadaan yang aseptis), tidak memerlukan peralatan khusus, murah dan hasil yang ditunjukkan representatif dan dapat dipercaya.

Pengujian larvasida masing-masing ekstrak daun jarak kepyar dalam konsentrasi $10 \mu \mathrm{g} / \mathrm{mL}, 100$ $\mu \mathrm{g} / \mathrm{mL}, 1000 \mu \mathrm{g} / \mathrm{mL}$ dengan kontrol positif yaitu Abate dan kontrol negatif yaitu air, diujikan terhadap larva nyamuk Aedes aegypti. Pengamatan dilakukan selama 24 jam setelah perlakuan dengan parameter kematian larva nyamuk.

Tabel 2. Data hasil pengamatan kematian larva nyamuk (Aedes aegypti) setelah pemberian ekstrak etanol daun jarak kepyar (Ricinus communis L.)

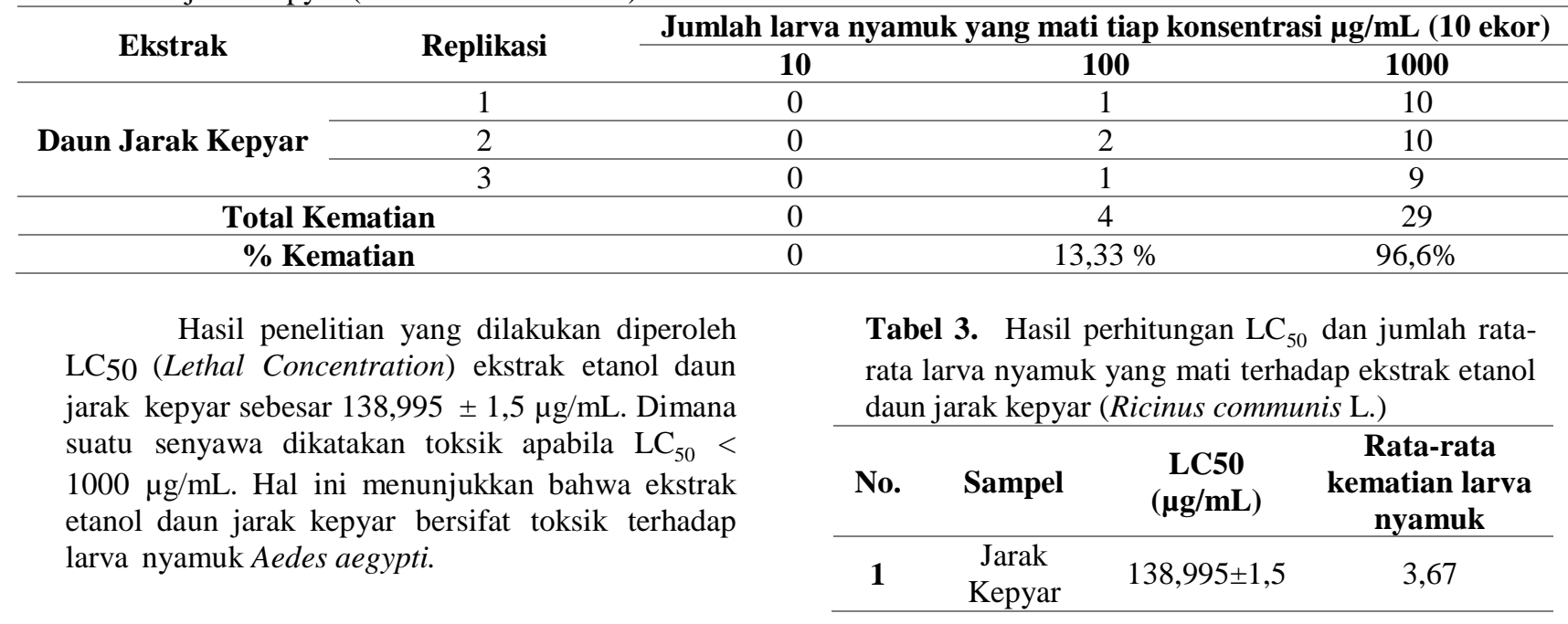


Adapun beberapa senyawa yang kemungkinan bersifat toksik dari ekstrak daun jarak kepyar (Ricinus communis L.) yaitu alkaloid, saponin dan flavonoid. Selanjutnya dilakukan Uji Kualitatif komponen kimia yang terkandung dalam ekstrak etanol daun jarak kepyar (Ricinus communis L.) dengan menggunakan metode KLT. Hasil identifikasi ini menunjukkan bahwa ekstrak etanol daun jarak kepyar positif mengandung senyawa alkaloid, saponin dan flavonoid.

Kandungan saponin dan alkaloid bertindak sebagai racun perut. Alkaloid berupa garam sehingga dapat mendegradasi membran sel untuk masuk ke dalam dan merusak sel dan juga dapat mengganggu sistem kerja syaraf larva dengan menghambat kerja enzim asetilkolinesterase. Terjadinya perubahan warna pada tubuh larva menjadi lebih transparan dan gerakan tubuh larva yang melambat bila dirangsang sentuhan serta selalu membengkokkan badannya disebabkan oleh senyawa alkaloid (Cania dan Setyaningrum, 2012).

Saponin mengandung glikosida dalam tanaman yang sifatnya menyerupai sabun dan dapat larut dalam air. Saponin dapat menurunkan aktivitas enzim pencernaan dan penyerapan makanan. Flavonoid merupakan senyawa pertahanan tumbuhan yang dapat bersifat menghambat makan serangga dan juga bersifat toksik. Cara kerja senyawa-senyawa tersebut adalah sebagai stomach poisoning atau racun perut yang dapat mengakibatkan gangguan sistem pencernaan larva Aedes aegypti, sehingga larva gagal tumbuh dan akhirnya mati (Haditomo, 2010).

Saponin dapat menurunkan tegangan permukaan selaput mukosa truktus digestivus larva sehingga dinding digestivus menjadi korosif. Dan menurut Banjo (2006), kandungan kimia saponin dan flavonoid mempunyai potensi sebagai larvasida Aedes aegypti, saponin merupakan senyawa berasa pahit menusuk dan dapat menyebabkan alergi serta sering mengakibatkan iritasi terhadap selaput lender, saponin dapat menghancurkan butir darah merah lewat reaksi hemolisis, bersifat racun bagi hewan (Aminah et al, 2001).

Tabel 4. Hasil identifikasi dalan senyawa ekstrak etanol daun jarak kepyar (Ricinus communis L.)

\begin{tabular}{cccc}
\hline \multirow{2}{*}{ Sampel } & \multicolumn{3}{c}{ Identifikasi } \\
\cline { 2 - 3 } & Alkaloid & Saponin & Flavonoid \\
\hline $\begin{array}{c}\text { Ekstrak } \\
\text { Daun } \\
\text { Jarak }\end{array}$ & + & + & + \\
Kepyar & & \\
\hline \multicolumn{2}{c}{ Keterangan } & $:(+):$ Ada \\
& & $(-)$ : Tidak Ada
\end{tabular}

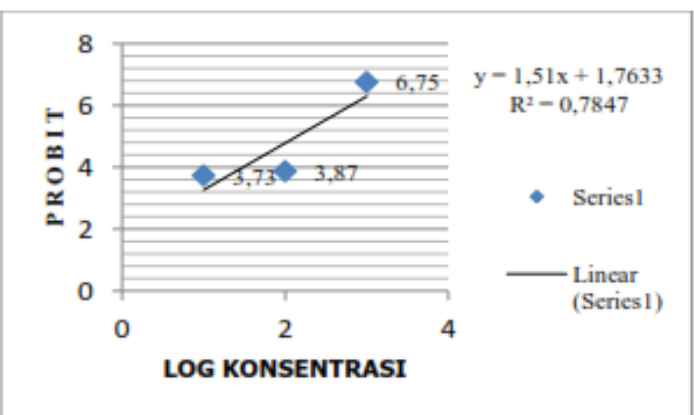

Gambar 1. Grafik Hubungan log konsentrasi ekstrak etanol daun jarak kepyar (Ricinus communis L.) terhadap harga probit sesuai persentase kematian.

\section{KESIMPULAN}

Hasil penelitian yang dilakukan dapat disimpulkan bahwa ekstrak etanol daun jarak kepyar (Ricinus communis L.) efektif sebagai larvasida terhadap larva nyamuk Aedes aegypti yang ditunjukkan dengan nilai LC50 sebesar 138,995 \pm $1,5 \mu \mathrm{g} / \mathrm{mL}$.

\section{DAFTAR PUSTAKA}

Aminah, NS et al. (2001) S. Lerak, D. Metel dan E. Prostata Sebagai Larvasida Aedes aegypti. Cermin Dunia Kedokteran No.131. Jakarta : Grup PT Kalbe Farma.

Aradilla, A.S. (2009) Uji Efektivitas Larvasida Ekstrak Etanol Daun Mimba (Azadiracta indica) terhadap Larva Aedes aegypti. (Skripsi) : Universitas Diponegoro.

Cania, E. dan Setyaningrum, E. (2012) Larvacide Effectiveness Test of the Legundi's Leaf (Vitex trifolia) Extract for Larvae of Aedes aegypti. Lampung: Medical Faculty of Lampung University.

Dirjen POM (1986) Sediaan Galenik. Jakarta: Departemen Kesehatan Republik Indonesia.

Haditomo, Indriantoro (2010) Efek Larvasida Ekstrak Daun Cengkeh (Syzygium aromaticum L.) Terhadap Aedes aegypti L. (Skripsi). Surakarta : Universitas Sebelas Maret.

Iqbal, J et al. (2012) Antioxidant, Antimicrobial, and Free Radical Scavenging Potential of Aerial Parts of Periploca aphylla and 
Ricinus communis. Journal ISRN

Pharmacology. 10.5402.56267.

Jena, J. \& Gupta, K.A (2012) Ricinus communis Lin, A Phytopharmacological Review. International Journal of Pharmacy and Pharmaceutical Sciences.

Ndione, RD, Faye O, Ndiaye, A., and Aufoutou JM. Toxic effects of neem products (Azadirachta indica A. Juss) on Aedes aegypti Linnaeus 1762 larvae. In African Journal of Biotechnology.

Rahman, A., Iqbal, C.M., William, JT. (2005) Biossay Techniques for Drug Development. Amsterdam: Horwood Academic Publishers

Sinaga, E. Ricinus communis. Linn. Pusat Penelitian dan Pengembangan Tumbuhan Obat UNAS. Diakses pada hari Rabu, 18 September 2013.

Steenis, V, C.G.G.J. (2008) Flora Untuk Sekolah di Indonesia, cetakan ke-12. PT. Pradnya Paramita : Jakata.

Widodo, W., Sumarsih, S. (2007) Jarak Kepyar Tanaman Penghasil Minyak Kastor Untuk Berbagai Industri. Yogyakarta: Kanisius. 